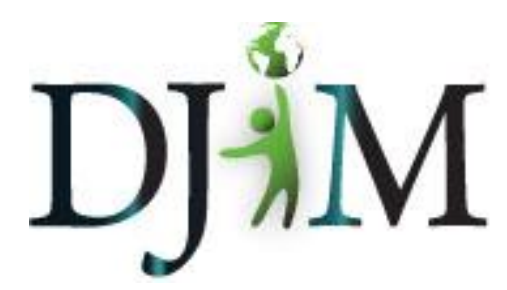

Volume 1 - Spring 2005 djim.management.dal.ca

\title{
Archives Users in the Digital Era: a review of current research trends
}

\begin{abstract}
About the Author(s): Carolyn Harris has an Honours degree in History and English from McMaster University. She is a first year student at Dalhousie's School of Library and Information Studies, where she has developed a great interest in archival studies. Her article was adapted from a literature review assignment in a Research Methods course. Ms. Harris plans to complete her MLIS in 2005-2006 in the Archives stream at the University of Toronto's Faculty of Information Studies.
\end{abstract}


In the 1980s, Paul Conway was one of the first to argue for the importance of research on archives users. User studies were then an unfamiliar territory for archivists and Conway presented a useful model for evaluating users, their information needs and their use of archival sources (1986). Conway encouraged archivists to take on a more active role as gatherers and processors of information, rather than remaining in their "traditional, passive custodial role" (1986).

Since those beginnings, the archival community has directed increasing attention to the study of users, and yet those who believe in the importance of being user-centred continue to express concern that research is lagging and that there has been little sharing of information with others in the field. It is true that formal user studies are difficult to design and undertake and frequently result only in frustration if they are not ultimately useful. Practical application is a key priority for archivists, and motivation is lacking where the end gains are not assured (Craig, 2003). Still, a growing number of archivists are calling on their peers to give greater consideration to users through applied research studies. Measurement, whether qualitative or quantitative, is a very valuable tool of evaluation for any service organization, even if undertaken only on a small scale (Craig, 1998).

The Internet has introduced a host of new challenges, but it also offers an opportunity to "unleash the power of archives" to greater numbers of users (Craig, 1998). With the migration of archival services online, archivists must understand how the Web has instilled users with new expectations of instant, effective and convenient access (Craig, 1998). Studies dealing with online users are a growing area of archives user studies. These studies build upon the basis of traditional research while targeting the unique characteristics and needs of a new user community (Craig, 1998).

Recently, Elizabeth Yakel and Deborah A. Torres have contributed to the discussion of effective user studies with their model of "archival intelligence." This concept is a measure of "a researcher's knowledge of archival principles, practices and institutions" and has three components: knowledge of archival theory, practices and procedures; strategies for reducing ambiguity or uncertainty in research; and "intellective skills," or the ability to read documents as representations (Yakel and Torres 52). Yakel and Torres set out to discern if there are salient characteristics which set apart novice and experienced archives users. Through in-depth interviews with 28 people, the researchers investigated users' understanding of archives jargon, internalization of archives rules, recognition of their own and archivists' limitations, individual search tactics and question-asking skills, the level of preparation preceding research, and their understanding of the representational relationship between surrogates and primary sources. Comparing their participants along each of these continuums of expertise, Yakel and Torres were able to distinguish the experiential and cognitive differences between novice and expert archives users. Their criteria and the concept of archival intelligence is, like Conway's model, a theory of use to archivists planning their own studies.

The Primarily History project is a massive ongoing study of how historians in the United States and the United Kingdom search for primary materials. Helen R. Tibbo's analysis of one phase 
of the project, the survey results from 700 historians in the United States, illustrates historians' continued reliance on print resources and their use of electronic tools. For example, the survey revealed that $63 \%$ of respondents visit the websites of archival repositories, a behaviour Tibbo suggests is a bridging behaviour, enough like contacting or visiting the repository itself that historians feel comfortable doing it. Tibbo's analysis makes distinctions between subgroups of the study population, revealing that junior faculty are more likely to use OPACs and the Web than senior faculty, that researchers at lower-ranked institutions are less likely to use electronic retrieval tools than their counterparts at highly-ranked schools, and that historians in certain areas (for example, biographical historians) use more kinds of search methods than those in others (for example, social historians). The Primarily History project will have much to contribute to archivists' understanding of the impact of technology on the information seeking habits of one of their primary user groups. Given the rate of technological development and the rise of a new generation of Web-savvy historians, these informationseeking habits will continue to change in the next five to ten years, requiring ongoing study.

As Yakel and Torres point out, what constitutes archival intelligence will continue to change with new developments in technology. As the number of surrogates that researchers can find increases and multiple versions of online representations are accessible, researchers' ability to visualize the relationship of the record to the actual item is becoming increasingly important (2003) [1]. Wendy Duff and Penka Stoyanova undertook a study of electronic archival displays based on the Rules for Archival Description (RAD) as seen from the user's perspective. Their findings suggest the kind of methods that would be useful in evaluating online finding aids. Duff and Stoyanova formed focus groups with a total of 27 participants who were presented with six different record displays. The groups were led through a structured discussion of each display, followed by an individual questionnaire and then an unstructured discussion to design their own "ideal" display. The discussion assessed the formatting of displays, the labels used and the elements of description themselves. Users' complaints and confusion highlighted the barriers to access erected through ineffective, un-user-friendly displays. Displays based on design principles were preferred over systems currently in place in archival repositories. Users objected to the sequencing, level of detail and even inclusion of some elements and expressed confusion over terminology and dates. The results of the study indicate the importance of flexibility in designing descriptive displays for users. Details useful and meaningful to archivists may just form roadblocks against access for archives users.

In line with Duff and Stoyanova's study of RAD displays, some researchers are focussing on the online environment in conducting similar studies. One example was the evaluation of the Pepper OnLine Archival Retrieval and Information System (POLARIS) Project at Florida State University, discussed by Burt Altman and John Nemmers. In order to define the parameters of a representative population, Altman and his colleagues surveyed social science faculty at the university about their opinions of the online finding aid. Quantitative use figures and log records already indicated a steady amount of use of the new tool, but the team sought qualitative measures because they recognized that statistics told them nothing of the effectiveness of searches or of user satisfaction. The Polaris Project study is a good example of useful methods for evaluating online systems; more generally, it also expresses the value of considering users and their experience in interacting with access tools. 
Studies of new encoding technologies are another area of online user research. In the United Kingdom, the "Linking EAD to Electronically Retrievable Sources" (or LEADERS) project is developing tools for professional use in delivering "digital archives documents in the form of encoded transcripts and digital images" (Sexton et al 34). LEADERS researchers are exploring Encoded Archival Description (EAD), Text Encoding Initiative (TEI) and Encoded Archival Context (EAC) as three related and potentially combinable encoding standards that could be used to provide digital access to archival material with a great level of depth and context alongside the usual content. James Roth's study focussed on EAD only and aimed to counter the criticism that repositories using EAD finding aids are ignoring their users' point of view. Because EAD is such a new technology, its reception in the archival community is still mixed, and if the quality of user access and use can be analyzed then it will help archivists assess the value of this new data structure standard.

Echoing the belief of the LEADERS project researchers, Amanda Hill discussed the necessity of adapting online finding aids to a use environment that lacks the mediation of archivists. Setting each collection within a context may be a necessary element of providing remote access, a possible necessity that could be confirmed through further research. Hill stated that online finding aids need to be more complete (thorough) and of better quality (subject indexed) (141-142). The interpretation required to provide context may be daunting because archivists traditionally describe holdings from a neutral perspective, but if a user-centred focus is desired, then interpretation is imperative (Hill 141-142).

One other challenge that the literature on online user studies brings to light is that of the independence of the researcher. Research has shown that archives users prefer informal sources of information - for example archivists, leads from secondary sources, and their own expertise - to formal sources like finding aids (Duff and Johnson 81). This preference is challenged, however, in the online environment. Do online users feel the same way? They are limited to online formal tools and have no informal alternatives. How and to what extent are online finding aids used? What are online users looking for in an archives website? Are archives websites well-designed and usable? How can they be made more so?

The Polaris project study indicated that researchers appreciate that online finding aids save them time because they can familiarize themselves with the collection before visiting the repository, or have the means to decide whether a trip will be useful at all (Altman and Nemmers 128). Similarly, Yakel and Torres noted that self-sufficiency was important to the majority of their subjects. Researchers would proceed without the assistance of an archivist even if it took longer to find what they needed (Yakel and Torres 73-75). This preference for 'getting the lay of the land' before jumping in to seek formal help has significant implications for the online environment. In what ways can the online resources of repository websites foster the independent discovery and build the expertise of researchers? What is the role of user education, and what are the topics and approaches with which it should be carried out? Yakel and Torres suggest that archival training for researchers could go beyond the context of a single institution to help researchers develop general archival research skills. User education needs to be ongoing and encompass archival principles and practice (Yakel and Torres 77). Roth contends that "archivists seem to feel that the level of awareness and knowledge of archival institution policies and procedures is less than desirable....But whose fault is this" 
(Roth 234)? Archivists need to educate their users if users are going to be informed and interested enough to participate in formal studies. If users appreciate and understand archival practice then they will be more receptive to providing feedback. The need continues for research of users' information needs and the problems they face when interacting with archival institutions. With areas of instructional need identified, archivists can better design educational programmes, the results of which should be shared with the broader community.

The growth of archives user studies provides evidence that the record may no longer hold an unchallenged place "at the heart of archival theory" (Duff and Johnson 79). Increasingly, archivists are recognizing that their mission involves not just the acquisition, description and preservation of archival material, but also the provision of effective access to that material for members of society. The importance of being user-centred in their services and tools is motivating archivists to engage in applied research to better understand the population they serve, an aim that holds great challenges, opportunities and importance in the digital era. 


\section{Reference}

Altman, Burt \& Nemmers, John R. The usability of on-line archival resources: the Polaris Project finding aid. American Archivist 64, 121-131.

Conway, Paul. Facts and frameworks: an approach to studying the users of archives. American Archivist 49, 393-408.

Craig, Barbara L. Old myths in new clothes: expectations of archives users. Archivaria 45, 118-126.

Craig, Barbara L. Perimeters with fences? or thresholds with doors? two views of a border. American Archivist 66, 96-101.

Duff, Wendy M. \& Johnson, Catherine A. Where is the list with all the names? informationseeking behaviour of genealogists. American Archivist 66, 79-95.

Duff, Wendy and Stoyanova, Penka. Transforming the crazy quilt: archival displays from a users' point of view. Archivaria 45, 44-79.

Hill, Amanda. Serving the invisible researcher: meeting the needs of online users. Journal of the Society of Archivists 25 (2), 139-148.

Roth, James M. Serving up EAD: an exploratory study on the deployment and utilization of Encoded Archival Description finding aids. American Archivist 64, 214-237.

Sexton, Anna, Turner, Chris, Yeo, Geoffrey, \& Hockey, Susan. Understanding users: a prerequisite for developing new technologies. Journal of the Society of Archivists 25 (1), 3449.

Tibbo, Helen R. Primarily history in America: how U.S. historians search for primary materials at the dawn of the digital age. American Archivist 66, 9-50.

Yakel, Elizabeth, \& Torres, Deborah A. Al: archival intelligence and user expertise. American Archivist 66, 51-78. 